PEREIRA AS; BERTONCINI O; SILVA GO; CASTRO CM; GOMES CB; HIRANO E; BORTOLETTO AC; MELO PE; MEDEIROS CAB; TREPTOW RO; DUTRA LF; LOPES CA; NAZARENO NRX; LIMA MF; CASTRO LAS; KROLOW ACR; SUINAGA FA; REISSER JUNIOR C. 2013. BRS Clara: cultivar de batata para mercado fresco, com resistência à requeima. Horticultura Brasileira 31: 664-668.

\title{
BRS Clara: cultivar de batata para mercado fresco, com resistência à requeima
}

\author{
Arione da S Pereira ${ }^{1}$; Odone Bertoncini ${ }^{2}$; Giovani O da Silva ${ }^{3}$; Caroline M Castro ${ }^{1}$; César B Gomes ${ }^{1}$; \\ Élcio Hirano²; Antonio César Bortoletto²; Paulo Eduardo de Melo ${ }^{3}$; Carlos Alberto B Medeirosi ${ }^{1}$; Rosa \\ O Treptow ${ }^{4}$; Leonardo F Dutra ${ }^{1}$; Carlos Alberto Lopes ${ }^{3}$; Nilceu RX Nazareno ${ }^{5}$; Mirtes F Lima ${ }^{3}$; Luis
} Antônio S de Castro ${ }^{1}$; Ana Cristina R Krolow ${ }^{1}$; Fábio A Suinaga ${ }^{1}$; Carlos Reisser Junior ${ }^{1}$

${ }^{1}$ Embrapa Clima Temperado, C. Postal 403, 96001-970 Pelotas-RS; arione.pereira@embrapa.br ²Embrapa Produtos e Mercado-Escritório de Canoinhas, C. Postal 317, 89460-000 Canoinhas-SC; ${ }^{3}$ Embrapa Hortaliças, C. Postal 218, 70351-970 Brasília-DF; ${ }^{4}$ UFPel-FCD, Depto. Ciência dos Alimentos, C. Postal 354, 96010-900 Pelotas-RS; ${ }^{5}$ IAPAR, R. Maximo João Kopp 274, Santa Candida, 82630-900 Curitiba-PR

\section{RESUMO}

'BRS Clara' é uma nova cultivar de batata para comercialização na forma fresca, liberada em 2010. Foi desenvolvida pelo Programa de Melhoramento de Batata da Embrapa, selecionada para aparência e rendimento de tubérculos, e resistência foliar à requeima, causada por Phytophthora infestans. Os tubérculos têm película amarela lisa, polpa creme, formato oval-alongado e olhos rasos. Seu potencial produtivo é alto. Na região Sul do Brasil, 'BRS Clara' apresentou rendimento de tubérculos mais elevado ou semelhante à cultivar Agata e não diferiu da 'Asterix'. No outono, apresentou rendimento total e comercial de tubérculos maiores que 'Agata', sendo que a superioridade foi relacionada à resistência à requeima da 'BRS Clara'. $\mathrm{Na}$ primavera, não diferiu da 'Agata' e 'Asterix'. O peso específico da 'BRS Clara' foi mais alto que da 'Agata' e mais baixo que da 'Asterix'. 'BRS Clara' mostrou baixa incidência de defeitos fisiológicos. Quanto à aptidão aos principais usos culinários, classificou-se como regularmente boa a boa para salada, ligeiramente boa para assar, e variou de ruim a boa para fritar na forma de palitos. A resistência ao esverdeamento dos tubérculos foi moderada. Apresentou moderada a alta resistência à requeima. Observações de campo indicam que 'BRS Clara' tem resistência moderada à pinta-preta e suscetibilidade ao mosaico (PVY) e ao enrolamento da folha (PLRV).

Palavras-chave: Solanum tuberosum, Phytophthora infestans, melhoramento genético.

\section{ABSTRACT}

'BRS Clara': A late-blight-resistant fresh market potato cultivar

'BRS Clara' is a new potato cultivar for the fresh market, released in 2010. It was developed by the Potato Breeding Program of Embrapa, selected for tuber appearance and yield, and foliar resistance to late blight caused by Phytophthora infestans. The tubers have yellow and smooth skin, cream colored flesh, elongated-oval shape and shallow eyes. It has high yield potential. In the South region of Brazil, 'BRS Clara' yielded higher or not different from Agata cultivar, and did not differ from 'Asterix'. In the autumn season, it yielded higher than 'Agata' for total and marketable tubers. This superiority was related to late blight resistance of 'BRS Clara'. In the spring season, it did not differ from 'Agata' and 'Asterix'. The specific gravity of 'BRS Clara' was higher than of 'Agata', and lower than of 'Asterix'. 'BRS Clara' had low incidence of physiological defects. In relation to the main culinary uses, it was rated as regularly good to good for salad, lightly good for baking, and varied from poor to good for French fries. The resistance to greening was moderate. It showed moderate to high resistance to late blight. Field observations indicate that 'BRS Clara' has moderate resistance to early blight, and susceptibility to mosaic (PVY) and leafroll (PLRV).

Keywords: Solanum tuberosum, Phytophthora infestans, cultivar, breeding.

(Recebido para publicação em 30 de julho de 2013; aceito em 7 de outubro de 2013) (Received on July 30, 2013; accepted on October 7, 2013)

\begin{abstract}
A cultivar BRS Clara foi desenvolvida pelo Programa de Melhoramento Genético da Embrapa formado pela Embrapa Clima Temperado, Pelotas-RS, Embrapa Produtos e Mercado- Escritório de Canoinhas-SC, e Embrapa Hortaliças, Brasília-DF. Lançada em 2010, foi codificada como clone 12-2, derivada de
\end{abstract}

um cruzamento de 'White Lady' (mãe) e 'Catucha' (pai) (Figura 1), efetuado em casa-de-vegetação na Embrapa Clima Temperado, no ano 2000. White Lady é uma cultivar húngara, liberada pelo programa da Pannon University of Agricultural Sciences, Keszthely, Hungria (The European Culivated Database, 2012).
A cultivar Catucha foi selecionada pela Epagri (Silva et al., 1995) derivada de cruzamento efetuado em casa-de-vegetação na Embrapa Clima Temperado, entre dois clones selecionados na Embrapa, '2CRI-1149-1-78' e 'C-999263-70'. O primeiro foi obtido do cruzamento entre a cultivar holandesa Recent 
e o clone CI-1086-22-75, enquanto o segundo foi selecionado da mistura de sementes sexuais de dez cruzamentos. Exceto 'C-1750-15-95', todos os demais clones incluídos na genealogia da 'BRS Clara' foram desenvolvidos pelo melhorista Delorge Mota da Costa.

As sementes sexuais da população híbrida que deram origem ao clone 122, foram semeadas sob telado, em 2000, na Embrapa Clima Temperado, obtendo os primeiros tubérculos para formar a primeira geração de seleção de campo.

O processo de seleção compreendeu quatro gerações efetuadas nos períodos de primavera de 2002 a 2005, nos campos experimentais de colaboradores da Embrapa Produtos e Mercado-Escritório de Canoinhas-SC (Pereira, 2003). Em 2006 o material foi submetido à limpeza clonal e, durante as safras de outono de 2007, primavera de 2007 e de 2008, o clone 12-2 foi submetido a ensaios comparativos em Canoinhas-SC, Pelotas-RS e Lapa-PR. Finalmente, nas safras de outono e primavera de 2009, e primavera de 2010, 'BRS Clara' foi submetida a ensaios de valor de cultivo e uso (VCU), utilizando como cultivares comparativas 'Agata' e 'Asterix'. Nestes ensaios foi realizada a caracterização morfológica, com 'BRS Clara' demonstrando distinguibilidade, homogeneidade e estabilidade fenotípica e genética. Concomitantemente aos ensaios para VCU, 'BRS Clara' foi validada junto a produtores do sul do país e efetuada multiplicação de sementes.

Com base na coloração amarela atrativa da película, superfície lisa, elevado potencial produtivo, e resistência à requeima, o clone 12-2 foi liberado como cultivar 'BRS Clara'.

\section{DESCRIÇÃO VARIETAL}

Descrições de planta e tubérculos da 'BRS Clara' foram obtidas de campos de avaliação conduzidos em Pelotas-RS.

Plantas - hábito de crescimento semiereto, porte médio, folhas moderadamente abertas e maturidade média de 100 a 105 dias (cerca de uma semana mais tardia que a cultivar Agata e cinco a sete dias mais precoce que Asterix).

Hastes - medianamente vigorosas,

Tabela 1. Médias de caracteres de rendimento e peso especifico das cultivares de batata BRS Clara, Asterix e Agata nos cultivos de outono e primavera, em Canoinhas-SC e Pelotas-RS (means of yield traits and specific gravity of 'BRS Clara', Asterix, and Agata potato cultivars in autumn and spring seasons, in Canoinhas, Santa Catarina state and Pelotas, Rio Grande do Sul state). Pelotas, Embrapa, 2013.

\begin{tabular}{|c|c|c|c|c|}
\hline \multirow{2}{*}{ Cultivar } & \multicolumn{2}{|c|}{ Produção (t/ha) } & \multirow{2}{*}{$\begin{array}{c}\text { Massa } \\
\text { média (g) }\end{array}$} & \multirow{2}{*}{$\begin{array}{c}\text { Peso } \\
\text { específico }\end{array}$} \\
\hline & Total & Comercial $^{2}$ & & \\
\hline \multicolumn{5}{|c|}{ Pelotas/Outono/ 2008} \\
\hline BRS Clara & $15,58 \mathrm{a}^{1}$ & $13,17 \mathrm{a}$ & 84,2 a & $1,071 \mathrm{~b}$ \\
\hline Agata & $12,75 \mathrm{~b}$ & $9,53 \mathrm{~b}$ & $56,0 \mathrm{~b}$ & $1,056 \mathrm{c}$ \\
\hline Asterix & $15,94 \mathrm{a}$ & $13,06 \mathrm{a}$ & $85,5 \mathrm{a}$ & $1,075 \mathrm{a}$ \\
\hline \multicolumn{5}{|c|}{ Canoinhas/ Outono/ 2009} \\
\hline BRS Clara & $17,50 \mathrm{a}$ & $10,84 \mathrm{a}$ & $70,4 \mathrm{a}$ & $1,075 \mathrm{~b}$ \\
\hline Agata & $8,50 \mathrm{a}$ & $5,06 \mathrm{a}$ & $71,6 \mathrm{a}$ & $1,069 \mathrm{c}$ \\
\hline Asterix & $17,17 \mathrm{a}$ & $7,66 \mathrm{a}$ & $80,7 \mathrm{a}$ & $1,078 \mathrm{a}$ \\
\hline \multicolumn{5}{|c|}{ Pelotas/ Outono/ 2009} \\
\hline BRS Clara & $19,40 \mathrm{a}$ & $16,33 \mathrm{a}$ & 86,0 a & $1,083 \mathrm{~b}$ \\
\hline Agata & $9,33 \mathrm{~b}$ & $5,73 \mathrm{c}$ & $41,4 \mathrm{c}$ & $1,077 \mathrm{c}$ \\
\hline Asterix & $16,87 \mathrm{a}$ & $13,10 \mathrm{~b}$ & $71,3 \mathrm{~b}$ & $1,090 \mathrm{a}$ \\
\hline \multicolumn{5}{|c|}{ Canoinhas/ Primavera/ 2010} \\
\hline BRS Clara & $20,83 \mathrm{a}$ & $6,83 \mathrm{a}$ & $51,0 \mathrm{a}$ & $1,078 \mathrm{~b}$ \\
\hline Agata & $17,53 \mathrm{~b}$ & $7,97 \mathrm{a}$ & 59,3 a & $1,063 \mathrm{c}$ \\
\hline Asterix & $21,83 \mathrm{a}$ & $6,67 \mathrm{a}$ & $65,8 \mathrm{a}$ & $1,085 \mathrm{a}$ \\
\hline \multicolumn{5}{|c|}{ Pelotas/ Primavera/ 2010} \\
\hline BRS Clara & $21,14 \mathrm{a}$ & $7,63 \mathrm{a}$ & $22,0 \mathrm{~b}$ & $1,079 \mathrm{~b}$ \\
\hline Agata & $18,26 \mathrm{a}$ & $8,30 \mathrm{a}$ & $25,1 \mathrm{~b}$ & $1,067 \mathrm{c}$ \\
\hline Asterix & $22,62 \mathrm{a}$ & $7,51 \mathrm{a}$ & $32,5 \mathrm{a}$ & $1,083 \mathrm{a}$ \\
\hline
\end{tabular}

${ }^{1}$ Médias seguidas pela mesma letra na coluna pertencem ao mesmo grupo, pelo teste de Scott \& Knott, a 5\% de probabilidade do erro (means followed by the same letter in the column belong to the same group, at the $5 \%$ level by the Scott \& Knott test); ${ }^{2}$ Tubérculos comerciais: tubérculos com diâmetro transversal superior a $45 \mathrm{~mm}$ (marketable tubers: tubers with transversal diameter larger than $45 \mathrm{~mm}$ ).

sem pigmentação de antocianina na base e com asas retas.

Folhas - inserção obtusa, moderadamente aberta, e sem pigmentação na nervura principal.

Folíolos - tamanho e largura médios, com enrolamento fisiológico, raramente coalescentes e ondulação débil nas bordas, e com frequência moderada de folíolos secundários.

Flores - baixa frequência de inflorescência, com pedúnculos medianos e não pigmentados. Corola - branca. Frutos - escassa presença no campo.

Tubérculos - formato oval-alongado, película amarela e lisa, com moderada resistência ao esverdeamento, olhos rasos, polpa creme, dormência média-curta (Figura 2).
Brotos - formato cônico e ápice fechado, base coloração azul-púrpura média e pouca pubescência, primórdios radiculares de intensidade baixa, com brotações laterais de comprimento mediano.

\section{DESEMPENHO AGRONÔMICO}

Na região Sul do Brasil, 'BRS Clara' produziu média mais elevada ou semelhante à da cultivar Agata e não diferiu significativamente da 'Asterix' (Tabela 1).

No outono, 'BRS Clara' apresentou rendimento total e comerciais (diâmetro transversal maior que $45 \mathrm{~mm}$ ) de tubérculos até $107,9 \%$ e $185,0 \%$, 


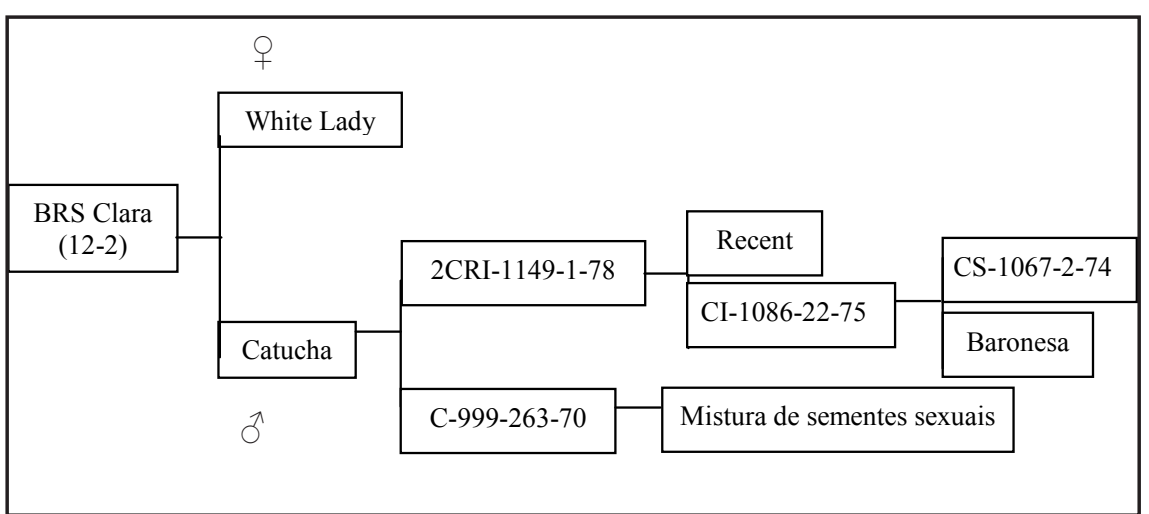

Figura 1. Genealogia da cultivar BRS Clara (pedigree of cultivar BRS Clara). Pelotas, Embrapa, 2013.

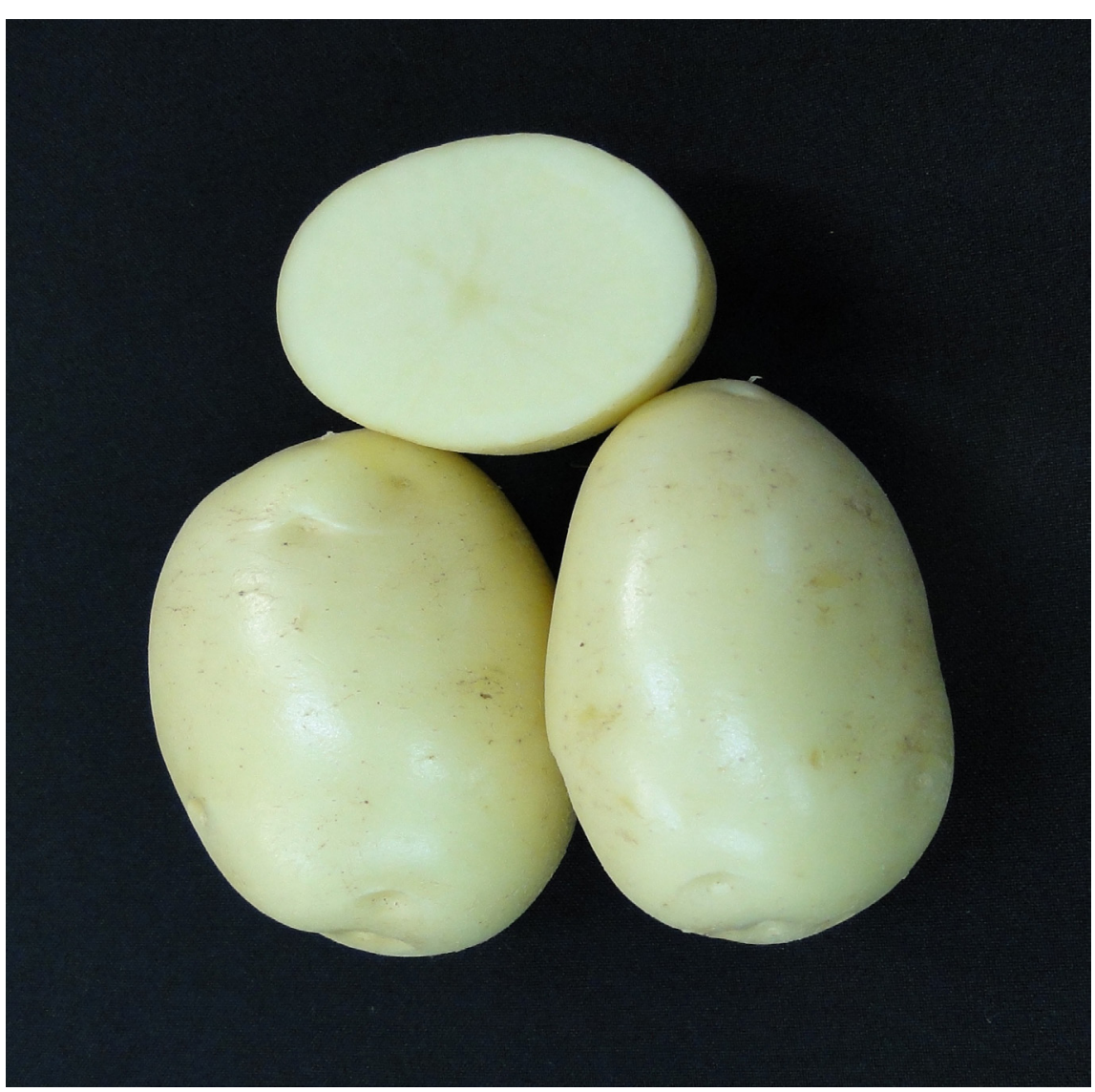

Figura 2. Cultivar BRS Clara (tubers of cultivar BRS Clara). Pelotas, Embrapa, 2013.

respectivamente, maior que 'Agata'. A superioridade esteve relacionada à ocorrência de requeima, comum neste cultivo. 'BRS Clara' também produziu tubérculos de massa média maior ou não diferente dos de 'Agata'.

$\mathrm{Na}$ primavera, a produtividade de 'BRS Clara' não diferiu, em geral, da 'Agata' e 'Asterix'. Sua massa média dos tubérculos foi menor apenas que 'Asterix', em Pelotas.

\section{CARACTERÍSTICAS DE OUALIDADE DE TUBÉRCULOS E USO}

Peso específico - O peso específico da 'BRS Clara' foi mais alto que da 'Agata' e mais baixo que da 'Asterix' (Tabela 1). No outono, 'BRS Clara' teve média de 1,076, ao passo que 'Agata' foi 1,067. Na primavera, os valores foram 1,078 e 1,065, respectivamente. Em comparação com Asterix, a cultivar BRS Clara apresentou peso especifico mais baixo consistentemente em todos os ensaios (1,081 e 1,083, respectivamente no outono e primavera).

Defeitos dos tubérculos - Em cinco ensaios, 'BRS Clara' mostrou uma mais baixa $(2 \%)$ incidência de crescimento secundário que as cultivares Agata (3\%) e Asterix (3\%). Apresentou um pouco mais $(8 \%)$ de tubérculos rachados que 'Agata' (6\%) e menos que 'Asterix' $(10 \%)$. Apresentou baixa (1\%) incidência de tubérculos com coração oco, não diferindo da 'Agata' $(1 \%)$. Em nenhuma das cultivares ocorreu mancha ferruginosa ou mancha chocolate.

Qualidade culinária - A cultivar BRS Clara foi avaliada quanto à aptidão aos principais usos culinários, cujas médias de qualidade estão apresentados na Tabela 2.

Salada - Em relação à aptidão para elaboração de salada, avaliada como palitos cozidos, a cultivar BRS Clara se classificou como regularmente boa a boa, por ter apresentado boa aparência e textura ligeiramente macia, regularmente úmida a ligeiramente seca, e ligeiramente coesa a esfarelada. Batatas para salada devem ter ligeira umidade, ligeira a regular coesão. Neste sentido, ainda que não tenha apresentado um bom desempenho, a cultivar Asterix foi de moderadamente boa a boa, devido à textura firme, ligeira a moderadamente úmida, sem esfarelar-se nem ser muito coesa. Comparativamente, a cultivar Agata foi classificada como regularmente boa, apresentando textura ligeiramente macia, úmida e coesa.

Assada - Para este tipo de uso, a cultivar BRS Clara foi classificada como ligeiramente boa, devido às características de textura firme, moderadamente úmida e coesa. Palitos cozidos de 'BRS Clara' mostraram boa aparência, mas na textura, caracterizaram-se por serem ligeiramente macios, secos e esfarelados. A cultivar Asterix foi classificada em qualidade como ligeiramente a moderadamente boa, com textura ligeiramente dura, ligeiramente úmida e pouco coesa. A cultivar Agata obteve classificação de regular a moderadamente boa, com menor dureza, maior umidade e moderada cremosidade. 
Tabela 2. Médias das características química e sensorial (qualidade geral ${ }^{1}$ ) da cultivares BRS Clara, Agata e Asterix (means of chemical and sensorial characteristics of cultivars BRS Clara, Agata, and Asterix). Pelotas, Embrapa, 2013.

\begin{tabular}{|c|c|c|c|}
\hline $\begin{array}{l}\text { Característica } \\
\text { Cultivar }\end{array}$ & 2008 & 2009 & 2010 \\
\hline \multicolumn{4}{|c|}{ Açúcares redutores (\%) } \\
\hline BRS Clara & $0,10 \mathrm{a}^{2}$ & $0,41 \mathrm{~b}$ & 0,26 a \\
\hline Agata & 0,10 a & $0,49 \mathrm{~b}$ & 0,23 a \\
\hline Asterix & 0,09 a & 0,08 a & 0,16 a \\
\hline \multicolumn{4}{|l|}{ Palitos fritos $^{1}$} \\
\hline BRS Clara & $3,80 \mathrm{~b}$ & $2,78 \mathrm{~b}$ & $3,73 \mathrm{~b}$ \\
\hline Agata & $1,20 \mathrm{c}$ & $0,75 \mathrm{c}$ & 6,33 a \\
\hline Asterix & $4,80 \mathrm{a}$ & 5,22 a & $6,20 \mathrm{a}$ \\
\hline \multicolumn{4}{|l|}{ Palitos cozidos $^{1}$} \\
\hline BRS Clara & $6,85 \mathrm{~b}$ & 7,98 a & 5,95 a \\
\hline Agata & $4,60 \mathrm{c}$ & $6,68 \mathrm{~b}$ & $4,24 \mathrm{~b}$ \\
\hline Asterix & 8,10 a & $5,07 \mathrm{c}$ & $6,08 \mathrm{a}$ \\
\hline \multicolumn{4}{|l|}{ Assada $^{1}$} \\
\hline BRS Clara & $5,25 \mathrm{c}$ & $6,82 \mathrm{~b}$ & 6,19 a \\
\hline Agata & 7,75 a & 7,42 a & $6,27 \mathrm{a}$ \\
\hline Asterix & $6,70 \mathrm{~b}$ & $6,64 \mathrm{~b}$ & $5,36 \mathrm{~b}$ \\
\hline
\end{tabular}

${ }^{1}$ Qualidade geral: 1= péssima, 9= ótima, representando a somatória das avaliações das características de aparência, textura e sabor (quality: $1=$ poor, $9=$ excelent, representing the sum of ratings of appearance, texture, and flavor). ${ }^{2}$ Médias seguidas pela mesma letra na coluna pertencem ao mesmo grupo, pelo teste de Scott \& Knott, a 5\% de probabilidade do erro (means followed by the same letter in the column belong to the same group, at the $5 \%$ level by the Scott \& Knott test).

Tabela 3. Intensidade de esverdeamento ${ }^{1}$ de tubérculos de batata das cultivares BRS Clara, Agata e Asterix (greening intensity of potato tubers for BRS Clara, Agata, and Asterix potato cultivars). Pelotas, Embrapa, 2013.

\begin{tabular}{lccccc}
\hline \multirow{2}{*}{ Cultivar } & $\mathbf{5}$ & $\mathbf{4}$ & $\mathbf{7}$ & $\mathbf{9}$ \\
\cline { 2 - 6 } & $1,7 \mathrm{a}^{2}$ & $3,7 \mathrm{a}$ & $7,3 \mathrm{~b}$ & $9,0 \mathrm{a}$ \\
\hline BRS Clara & $1,7 \mathrm{a}$ & $3,7 \mathrm{a}$ & $7,0 \mathrm{a}$ & $9,0 \mathrm{a}$ \\
Agata & $1,7 \mathrm{a}$ & $4,0 \mathrm{~b}$ & $7,7 \mathrm{c}$ & $9,0 \mathrm{a}$ \\
Asterix &
\end{tabular}

${ }^{1}$ Intensidade de esverdeamento: $1=$ ausente/muito fraco, $3=$ fraco, $5=$ médio, $7=$ forte e $9=$ muito forte (greening intensity: $1=$ absent/very light, $3=$ light, $5=$ medium, $7=$ strong and $9=$ very strong). ${ }^{2}$ Médias seguidas pela mesma letra na coluna pertencem ao mesmo grupo, pelo teste de Scott \& Knott, a 5\% de probabilidade do erro (means followed by the same letter in the column belong to the same group, at the $5 \%$ level by the Scott \& Knott test).

Palitos - Quanto à elaboração de palitos fritos, a cultivar BRS Clara se classificou variando de ruim a boa, devido à coloração de amarelo escuro a amarelo dourado, textura externa de semi-mole a regular, e de pouca crocância com tendência a coriácea. A cultivar Asterix, que é muito utilizada para fritura, apresentou palitos de coloração amarelo claro, boa textura externa e de moderada crocância. A cultivar Agata, testados quanto à suscetibilidade ao esverdeamento. Os tubérculos ficaram expostos à luz natural somente durante o dia. A intensidade de esverdeamento externa baseada em escala de nove pontos $(1=$ ausente/muito fraco, $3=$ fraco, $5=$ médio, $7=$ forte e $9=$ muito forte), foi realizada aos 2, 4, 7 e 9 dias, em tubérculos recém-colhidos e lavados (Tabela 3). Aos dois dias de exposição à luz, a intensidade de esverdeamento das três cultivares foi muito fraca; aos quatro dias, foi mais fraca nas cultivares Agata e BRS Clara que na Asterix; aos sete dias, o esverdeamento estava forte nos tubérculos de Agata, e mais forte ainda nas cultivares BRS Clara e Asterix; e aos nove dias todas as três cultivares estavam com intensidade de esverdeamento muito forte.

\section{REAÇÃO A DOENÇAS}

'BRS Clara' mostrou-se resistente à requeima (Phytophthora infestans), conforme está apresentado na Tabela 4. Os resultados obtidos em três ensaios, mostrando os baixos valores da área abaixo da curva de progresso da doença (AACPD), sugerem que esta cultivar foi de alta a moderadamente resistente à requeima em relação à testemunha 'Agata' (Gomes et al., 2009; Coila et al., 2010).

O grau de resistência apresentado por 'BRS Clara' não prescinde do emprego de pulverizações com fungicidas ou produtos alternativos para manejar os sistemas de produção convencional ou orgânico, desde que existam condições favoráveis ao desenvolvimento da requeima.

Observações de campo indicaram que 'BRS Clara' possui resistência moderada à pinta-preta causada pelo fungo. Também se verificou em ensaios conduzidos a campo e avaliações, aos 45-50 dias do plantio dos tubérculos, que 'BRS Clara' apresentou suscetibilidade ao mosaico causado pelo vírus $\mathrm{Y}$ da batata [Potato virus Y (PVY)] e ao enrolamento da folha [Potato leafroll virus (PLRV)], considerando expressão de sintomas em plantas e utilização de antissoros específicos, em teste DAS-ELISA (double antibody - Enzyme linked immunosorbent assay; Clark \& Adams, 1997). Em relação a outras 
Tabela 4. Médias de área abaixo da curva de progresso da doença (AACPD) e reação da BRS Clara e de outras cultivares de batata a Phytophthora infestans (mean area under disease progression curve and the reaction of 'BRS Clara' and of other potato cultivars to Phytophthora infestans). Pelotas, Embrapa, 2013.

\begin{tabular}{|c|c|c|c|c|c|c|}
\hline \multirow{2}{*}{ Cultivar } & \multicolumn{2}{|c|}{2008} & \multicolumn{2}{|c|}{2009} & \multicolumn{2}{|c|}{2010} \\
\hline & AACPD & Reação & AACPD & Reação & AACPD & Reação \\
\hline BRS Clara & $1,6 \mathrm{c}^{1}$ & $\mathrm{AR}^{2}$ & $192,5 \mathrm{c}$ & AR & $198,8 \mathrm{~b}$ & MR \\
\hline Agata & $572,6 \mathrm{a}$ & S & $616,5 \mathrm{a}$ & S & $574,1 \mathrm{a}$ & S \\
\hline BRS Eliza & $447,9 \mathrm{~b}$ & MR & $675,8 \mathrm{a}$ & $\mathrm{S}$ & $237,3 \mathrm{~b}$ & MR \\
\hline EPAGRI Catucha & $370,1 \mathrm{~b}$ & MR & $355,4 \mathrm{~b}$ & MR & $164,3 \mathrm{~b}$ & MR \\
\hline CIP392.617-54 & $0,5 \mathrm{c}$ & AR & $18,3 \mathrm{c}$ & AR & $0,0 \mathrm{c}$ & AR \\
\hline
\end{tabular}

${ }^{1}$ Médias seguidas pela mesma letra, na coluna, pertencem ao mesmo grupo, pelo teste de Scott \& Knott, a 5\% de probabilidade do erro (means followed by the same letter in the column belong to the same group, at the $5 \%$ level by the Scott $\&$ Knott test). ${ }^{2} \mathrm{AR}=$ altamente resistente; $\mathrm{MR}=$ moderadamente resistente; $\mathrm{S}=$ suscetível $(\mathrm{AR}=$ highly resistant; $\mathrm{MR}=$ moderately resistant; $\mathrm{S}=$ susceptible).

doenças, não se tem ainda informações sobre o comportamento dessa cultivar.

\section{MANEJO}

Em geral, as práticas de manejo de cultivo da 'BRS Clara' são comuns àquelas utilizadas para outras cultivares de ciclo médio. Embora o limitado número de estudos e observações sobre manejo, 'BRS Clara' tem mostrado boa resistência ao herbicida metribuzin em aplicações de acordo com o rótulo do produto.

Quanto ao manejo de doenças, embora apresente alta resistência à requeima, não dispensa a aplicação de fungicidas, em especial sob condições de alta umidade e baixa temperatura, e requer pulverizações rotineiras para o controle da pinta preta. Para obtenção de tubérculos de alta qualidade, o ponto de colheita deve ser cuidadosamente observado, visando identificar o momento que combine o máximo de produção sem perda de qualidade de película em relação a brilho e aspereza. Avaliada em Canoinhas-SC, foi observado que a dessecação deveria ser realizada no máximo aos 100 dias após o plantio, para a obtenção de tubérculos com boa qualidade de película e sem maior redução do rendimento de tubérculos (Silva et al., 2013).

\section{PERFIL MOLECULAR}

O perfil molecular da 'BRS Clara' foi obtido para os lócus de microssatélites STPoAc58, STG0016, STG0025, STI0012, STI0030 e STI0032. As rea- ções de PCR e as condições de eletroforese seguiram o protocolo descrito por Ghislain et al. (2009). Os produtos da PCR foram separados em eletroforese de gel de poliacrilamida $6,5 \%$, no sistema analisador de DNA LI-COR modelo 4300 (LI-COR Biosciences). O tamanho dos alelos, expresso em pares de base (pb), foi determinado com o marcador de peso molecular IRDye 50-350 utilizando o software de análise de imagens SAGA (LI-COR Biosciences). Foram caracterizadas juntamente com a 'BRS Clara' as cultivares de película amarela amplamente cultivadas no Brasil Agata e Atlantic. O perfil molecular da 'BRS Clara' é distinto da cultivar Agata em todos os lócus analisados, exceto para o STG0025. Na comparação com a cultivar Atlantic, a 'BRS Clara' apresentou padrão molecular distinto para os lócus STPoAc58, STG0016, STI0030 e STI0032. Os alelos identificados na 'BRS Clara' em cada loco de microssatélite analisado são: STPoAc58 (263 e $249 \mathrm{pb})$; STG0016 (154, 150 e $148 \mathrm{pb}$ ); STG0025 (219 e 215 pb); STI0012 (200, 188 e $184 \mathrm{pb})$; STI0030 (126, 110 e 105 pb); STI0032 (143, 137 e 131 pb).

\section{PROTEÇÃO, DISPONIBILIDADE DE SEMENTE E LICENCIAMENTO}

Informações sobre batata-semente podem ser obtidas junto à Embrapa Produtos e Mercado-Escritório de Ca-

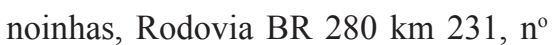
1151 Bairro Industrial 2, C. Postal 317, 89460-000 Canoinhas-SC.
Fone (47) 3624-0127, 3624-0195 e 3624-2077. E-mail: ecan.spm@embrapa.br. http://spm.sede.embrapa.br/ produtos/produtos/

Esta cultivar está registrada sob o número 27275 e protegida sob o certificado número 20110142, em nome da Embrapa, no Ministério de Agricultura, Pecuária e Abastecimento.

\section{AGRADECIMENTOS}

Os autores agradecem ao $\mathrm{CNPq}$, pelas bolsas concedidas e suporte financeiro parcial ao Programa de Melhoramento Genético da Embrapa.

\section{REFERÊNCIAS}

CLARK MF; ADAMS AN. 1977. Characteristics of the microplate method of enzyme linked immunosorbent assay for the detection of plant viruses. Journal of General Virology 34: 475-483.

COILA VHC; GOMES CB; PEREIRA AS; STÖCKER CM. 2010. Avaliação da resistência de genótipos de batata (Solanum tuberosum L.) a requeima (Phytophthora infestans). In: CONGRESSO DE INICIAÇÃO CIENTÍFICA, 19, e ENCONTRO PÓSGRADUAÇÃO da UFPel, 12, Pelotas. Anais eletrônicos... Pelotas: UFPel. Disponível em: http://www.ufpel.edu.br/cic/2010/cd/pdf/CA/ CA 01009.pdf. Acessado em 11 de dezembro de 2012.

GHISLAIN MG; NÚÑEZ J; HERRERA MR; PIGNATARO J.; GUZMAN F.; BONIERBALE M.; SPOONER DM. 2009. Robust and highly informative microsatellitebased genetic identity kit for potato. Molecular Breeding 23: 377-388.

GOMES CB; PEREIRA AS; STOCKER CM; BOSENBECKER VK. 2009. Reação de genótipos de batata à requeima (Phytophthora infestans) Pelotas: Embrapa Clima Temperado. 16p. (Embrapa Clima Temperado. Boletim de pesquisa e desenvolvimento, 83).

PEREIRAAS. 2003. Melhoramento genético. In: PEREIRA AS; DANIELS J (eds). O cultivo da batata na região Sul do Brasil. Brasília: Embrapa Informação Tecnológica/Pelotas: Embrapa Clima Temperado. p. 105-124.

SILVA ACF; SOUZA ZS; MULLER JJV; VIZZOTO VJ; REBELO JA; ZANINI NETO JA; COSTA DM; BERTONCINI O. 1995. EPAGRI 361-Catucha: nova cultivar de batata para Santa Catarina. Agropecuária Catarinense 8: 22-25.

SILVA GO; PEREIRA AS; SUINAGA F; PONIJALEKI R. 2013. Qualidade de pele e produtividade da cultivar de batata BRS Clara. Horticultura Brasileira 31: 613-617.

THE EUROPEAN CULIVATED DATABASE. 2012. White Lady. Disponível em http:// www.europotato.org/display_description. php?variety_name $=$ WHITE $\% 20$ LADY. Acessado em 10 de dezembro de 2012. 